from the anterior corpus striatum to the anterior limit of the nucleus gracilis. The plates are large in size and of exceptional clarity. One of each pair is stained and labelled to show nuclear and the other to show fascicular structures, and co-ordinates measured from the sagittal and inter-aural planes are clearly marked.

These atlases represent a considerable advance over their predecessors, which have concentrated mainly on the diencephalon, and the inclusion of the co-ordinates of medullary structures will be of considerable value to students of the reticular formation of the brain stem. One may perhaps regret that, in work of this quality, no attempt has boen made to provide a guide to the identification of nuclei in terms of their finer anatomy other than to refer the reader to "original research articles in the various anatomical journals" which incidentally are not contained in the bibliography; and since the authors direct attention to the dangers of fouling the tentorium cerebelli with the advancing electrode tip it would have been holpful had, at the same time, the co-ordinates of this structure been illustrated on the appropriate sections. A further, and surprising, omission is a failure to define the horizontal plane of orientation in terms of extra-cranial structures-a feature which may prove disadvantageous to usors of non-standard stereotaxic instruments. But such criticisms are small by comparison with the value of these two companion volumes whose appearance will bo wolcomed by all working with the cat and the monkey whether or not they are concerned with stereotaxic methods.

\section{THE GIFTED CHILD}

The Year Book of Education 1962

The Gifted Child. Joint Editors, Prof. George Z. F. Bereday and Prof. J. A. Lauwerys. Pp. xiv +541 . (Published in Association with the University of London Institute of Fducation and Teachers College, Columbia University, New York, by London: Evans Brothers, Ltd., 'Twenty-fourth edition, 1962.) 638 .

HIS book contains sufficient educational dynamite to turn the education committee of every local education authority into a fratricidal bear garden. For there is war-and war to the deathbetween the views of Sir Cyril Burt and those of Prof. J. P. Guilford of the University of Southern California.

Sir Cyril Burt, the convinced Platonist, in a fine historical account of the development of the intelligence quotient (T.Q.) idolatry which some of us consider is slowly destroying the educative value of all conventional 'oducation', tells us that the gifted child, as defined by him and those who share his views, is "as a rule, taller, stronger and healthier than tho avorage. He is on the wholo free from abnormalities of whatever kind, physical, intellectual, emotional and nervous. Until they begin to specialize, most gifted childrer aro gifted all round". Thoy are, indeed, the very people whom Plato would have set aside to provide the upholders and preservers of the changeless State, and also, of course, of the small core of philosopher-kings. They are those whom Samuel Smiles would also have approved of most.
In contrast take this paragraph from Prof. Guilford's very important article. "And which children should be regarded as gifted? The current answer, at least in many places, is the student with a high I.Q. and with high grades (the two indicators usually strongly correlated). Such children may be those who please their teachers most because they learn more rapidly under conditions that call for uniformity of thinking and acting within a group. The moro creative child, who may be higher in divergont thinking abilitios and not so high in cognitive abilities emphasized in present tests and examinations, may be a source of annoyance and not recognized as gifted. And how many children who are potential composers or artists, who are very high in concrete intelligence but not so high in academic intelligence, are missed when the 'gifted child' is selected."

It was worth publishing this fascinating volume even if only to make the epoch-making researches of Prof. Guilford known to a wide non-specialist world public, and his article on parametry and categories of talent is doubtless the most exciting in this book. The wide researches carried out under his guidance on young adults, and supported by funds from the U.S. Office of Naval Research and the U.S. Office of Education, have established that there are already fifty-five different primary abilities which have beon recognized; there are probably many more. For the past thirty years thousands of educationists and millions of ordinary people, believing that there is more faith in honest doubt, have found it hard to accept the view that the I.Q. test could really bo adequate as a measure of human intellectual ondowment. But we have boon unable, through lack of the necessary research funds and research workers, to prove this sciontifically. But thanks to Prof. Guilford and tho U.S. Office of Naval Research we can now say with Prof. E. Paul Torrance, who writes on "Measurement and Development of the Creativo Thinking Abilities", that oducators "aro beginning to recognize that the human mind is far more complex than can be inferred from present-day methods of identifying 'the gifted', and, in particular, that traditional measures of I.Q. tap only a few of man's thinking abilities". Indeed, Torrance is able to affirm "if present mothods of identifying talent had been applied they would have eliminated many of the great men of the past".

The tragedy for England and Wales at this time is that the development of "Beloe" examinations in all secondary modern schools and streams is going to confine education for an ever-greater percentage of our pupils within the cast-iron boundaries of the traditional academic syllabus and examination. The opportunity for the teacher to develop in every one of his pupils the peculiar and valuable endowment that nature has given him is slowly being eroded away. As Prof. Guilford states, "If each child is to be given the opportunity to make the most of his outstanding assets, those outstanding assets will have to be rocognizod. They cannot be recognized by the use of an I.Q. test whose coverago of that great complex of intellect is severely limited to a few qualities that have predicted grades that are also severely limited in intellectual scope".

There are forty articles in this volume and they survey the developments in the chosen field from many points of view and discuss soloction proceduros in many countries. Every educational thinker and educational politician should dip into it.

C. H. Dobinson 